\title{
Research into Knowledge Management Based Young Teacher Training Mechanism at Colleges and Universities
}

\author{
Xiuling Liu \\ School of Foreign Studies; Xi'an University of Arts and Science; Xi'an, Shaanxi; China; 710065
}

Keywords: Knowledge management; Young teachers; Explicit knowledge; Tacit knowledge

\begin{abstract}
Young teachers under take the main teaching tasks at colleges and universities, so their teaching ability and teaching effect affect the overall level and quality of college teaching work to a large extent. Starting from the theory of knowledge management and aiming at features of college teachers, this paper analyzes the contents and process of teachers' knowledge management, and establishes knowledge management based young teacher cultivation mechanism according to such contents and process.

Young teachers under take the main teaching tasks at colleges and universities, so their teaching ability and teaching effect affect the overall level and quality of college teaching work to a large extent. Therefore, how to rapidly improve young teachers' quality and establish an excellent team of young teachers is a long-run plan affecting the future development of higher education.

The thought and practice of knowledge management first originates from corporate management with digital technology as the background. It is generally believed that knowledge management refers to the theory and technology used by enterprises or organizations to obtain, create, store, share or apply knowledge to improve performance on the premise of insisting on people first. It is not only the response to the knowledge society and information explosion in theory and practice, but also increasingly becomes the realistic response and core motivation for an organization to achieve success. Knowledge management emphasizes the identification of knowledge within an organization, the formulation of incentive programs based on knowledge and promoting the implementation of knowledge sharing strategy, etc. Schools are important place to select, organize and disseminate knowledge. Teachers not only undertake the above functions, but also are the main body of innovating knowledge, and their own professional development is realized through internalizing and externalizing knowledge. Therefore, to use knowledge management technology and concept to promote rapid growth of teachers and construct a mechanism to cultivate young teachers has become a new path for the development of colleges and universities and teachers' teaching ability is improved through young teachers' knowledge management.
\end{abstract}

\section{Basic Theory of Knowledge Management}

The core concept of knowledge management is the transformation and innovation of knowledge. In the early 1990s, the SECI model of mutual transformation between explicit knowledge and tacit knowledge proposed by Japanese scholars is a classic theory of knowledge transformation and innovation.

The SECI(Socialization; Externalization; Combination; Internalization) Model is believed to be a rigorous method used to describe the generation, transference and recreation of knowledge within an organization. To put it simple, this model contains: an interactive power-transference; two forms of knowledge -explicit knowledge and tacit knowledge; three levels of social integration -individuals, groups and organizations; four processes of "creating knowledge" -socialization, externalization, combination and internalization.

Knowledge is not static, but is constantly changing. The tacit knowledge hidden in the ritual activities is the key to all levels of human knowledge, by analogy, and explicit knowledge is discrete in consciousness, the image can be expressed in writing. Tacit knowledge is the basis of explicit knowledge, explicit knowledge and tacit knowledge is transformed, they not only are the premise, but also under certain conditions to form spiral conversion, the conversion process is the process of knowledge sharing and innovation. 
Knowledge management (KM) is a process of creating value by intangible assets organized by an organization. "It is a combination of knowledge based systems, artificial intelligence, software engineering improvement, human resource management, and organizational behavior". The rapid rise of knowledge management has brought about great change of management mode and great change of management thought. The so-called knowledge management is to help people to reflect on the knowledge, help and support the development of people to exchange knowledge technology and internal structure, and help people acquire knowledge sources, promote the knowledge exchange between them; knowledge management is the use of collective intelligence, adaptability and innovation ability, improve organizational performance and employee skills.

\section{Teachers’ Knowledge Management}

Jin Yuzhi and Liang Zhanhua, etc. think that teacher knowledge management is a process for teachers to sustainably obtain, store, share professional teaching knowledge and apply them in innovation. Through the establishment of an effective knowledge management system and system, increasing the share and the mobility of teachers' professional knowledge, think that teachers' knowledge management refers to teachers' personal production, acquisition, collection, organization, dissemination, sharing, use and creation of new knowledge, the system process of the use of the collective wisdom to promote the teacher's professional growth and enhance the overall school strain and the innovation ability. In a knowledge-based society, knowledge and individuals with knowledge are the most important assets of an organization. For schools, teachers and the potential knowledge in teachers is to enhance the competitiveness of the school an important source of power. Through the management of teacher knowledge, young teachers can grow rapidly on the basis of senior teachers.

Contents of Teachers' Knowledge Management. Knowledge management means to manage the acquisition, storage, application and circulation of knowledge so as to improve the acquisition and application of knowledge by using tools, means and methods that can improve the efficiency of knowledge itself. The ultimate goal of knowledge management is to create knowledge, share knowledge and use knowledge through the collaborative process of groups, and directly improve the efficiency and competitiveness of knowledge. Therefore, the core of knowledge management and the emphasis is to create a mechanism and platform of tacit knowledge and explicit knowledge and animation, into the accumulation and sharing of knowledge base through the tacit knowledge representation mechanism of each member by sharing this knowledge base to continue to learn and grow. The essence of knowledge management is knowledge innovation and sharing, it does not care how much knowledge, but the use of existing knowledge to innovate, create new value, let people need knowledge, use the knowledge easily.

The teacher's knowledge is a kind of comprehensive individual knowledge, which contains the theoretical knowledge of public, but also contains individual practical knowledge; it contains both explicit knowledge and tacit knowledge. Therefore, the content of teacher knowledge management is from two aspects: explicit knowledge and tacit knowledge.

(1) Organize and classify teachers' explicit theoretical knowledge, which includes the collection, writing, materials and documents of schools and teachers. This is the basic content o teachers' knowledge as well as the foundation of other contents of teacher knowledge management.

(2) Achieve effective acquisition and accumulation of teacher knowledge. The dynamic of teachers' knowledge that teachers must constantly update and enrich their knowledge, this is the school to help and support teachers to update and enrich knowledge of teachers to realize effective knowledge acquisition and accumulation as an important task of the teachers' knowledge management.

In order to effectively accumulate the knowledge of teachers, should pay attention to the existing theory of receptive learning of explicit knowledge, to get accurate, timely and effective information from the external environment, including access to relevant information published in the latest, browse the latest news released by the Internet, and then get the primary information screening, review, and procedures of the system, has been combined with his knowledge and experience in this 
area for further analysis, so that the old and new knowledge together naturally. At the same time, we should pay attention to the construction of information knowledge system in the teaching practice, in the interaction with students and other teachers.

(3) To realize the transformation of teachers' explicit knowledge and tacit knowledge in order to create knowledge and realize the effective increment of knowledge. An important task of teacher knowledge management is knowledge innovation to promote faculty members, through the expansion of knowledge innovation organization knowledge accumulation, development to promote the professional development of teachers and schools, and the essence of knowledge innovation is the process of forming, transferring and adding value to knowledge through the interaction between implicit knowledge and explicit knowledge.

(4) Promote effective exchange and sharing of teachers' knowledge. Teacher's work is individual, and a good teacher can affect a student's entire life, but any student is not the result of a single teacher's education, but the result of education by many teachers within a long period of time. The coordination and cooperation between teachers is the premise to achieve the overall work of the school effectively, so the knowledge exchange and sharing between teachers is not only the premise of the development of the school, but also the premise of teacher growth and student development. To promote and realize the effective exchange and sharing of knowledge among teachers has become an important part of teacher knowledge management.

Process of Teachers' Knowledge Management.

(1) Knowledge acquisition. Knowledge acquisition is a process for teachers to acquire the knowledge they need. For their tacit knowledge can be obtained through reflection and practice; for the retrieval of knowledge can be obtained through other teachers' tacit knowledge and explicit knowledge; the other teachers can promote teaching through the establishment of group discussion, interview and other forms of access to senior teachers.

(2) Knowledge expression. Knowledge expression is a process of refining, classifying, encoding, summarizing, standardizing, and integrating the knowledge before it is stored.

(3) Knowledge storage. The stage of knowledge storage is the process of storing and storing personal knowledge acquired by teachers in the form of written or electronic stored in personal knowledge base. All teachers' personal knowledge base forms the knowledge base of school teachers, namely, teacher organization knowledge base. The purpose of knowledge storage is two: first, the storage of knowledge is conducive to the convenience of teachers' extraction and effective use; the two is to store knowledge in the form of knowledge map in favor of knowledge sharing.

(4) Knowledge sharing. Knowledge can only be shared to sublimate its value. Therefore, knowledge sharing is an important step in the process of teacher knowledge management. Sharing enables knowledge to be openly discussed and brainstorming to form knowledge alliances. The sharing of teacher knowledge is divided into explicit knowledge sharing and tacit knowledge sharing. The combination of the process of knowledge sharing explicit knowledge and it is the main way of knowledge map; tacit knowledge sharing is the process of socialization of knowledge, is the main way of exchanges and cooperation between the teachers' minimalist. The direct purpose of knowledge sharing is to enrich teachers' personal knowledge, which is to improve teachers' knowledge innovation ability. Teacher knowledge sharing can stimulate the potential of teachers to innovate professional knowledge, and the school's overall knowledge assets have also been value-added.

(5) Application of knowledge. Knowledge application is one of the purposes of teacher knowledge management, and it is also one of ways for teachers to acquire and update knowledge. The application of knowledge can internalize their explicit knowledge, knowledge application of reflection and can realize the externalization of tacit knowledge. Therefore, knowledge application is the teachers' tacit knowledge and explicit knowledge circulation process of transformation.

It is also the process of externalization and internalization of knowledge. The application of knowledge can realize the transformation between teacher's explicit and tacit knowledge, namely internalization and externalization of knowledge.

(6) Knowledge innovation. Knowledge innovation is the core idea of teacher knowledge 
management. The stage of knowledge innovation is the process that teachers apply existing knowledge to discover new knowledge and laws and renew their current knowledge system. This process is the process of transferring teachers' existing knowledge into new knowledge. The main way of teacher knowledge innovation is practice and scientific research. Knowledge innovation not only expands the breadth and depth of teachers' professional knowledge, but also provides an opportunity for schools to create new organizational culture.

\section{Knowledge Management Based Young Teacher Cultivation Mechanism at Colleges and Universities}

Combined with the Analysis of the Content and Process of Teacher Knowledge Management, Applying. knowledge management to the cultivation of young college teachers, we can establish the following system to promote the growth of young teachers.

Establish Tutorial System. For the acquisition of knowledge, a tutorial system can be established to exchange and inherit experiences, and it actually also stimulates the knowledge circulation and update within a school or organization. Secondly, experienced teachers can cooperate with young teachers in teaching. Teachers' teaching experience and professional literacy belong to tacit knowledge, so the most effective way is face-to-face interaction. Cooperative teaching can promote the extension of teaching experience between teachers.

Establish a Scientific Research Team to Promote Internal Knowledge Sharing. Establish a scientific research team, pay attention to knowledge management within a team and make experienced professors' implicit knowledge transform into explicit knowledge so as to promote the rapid growth of young teachers within the team and establish knowledge alliance between various departments. Emphasize the establishment of knowledge alliance and integrating knowledge between various departments as well as relevant enterprises and scientific research institutions. Implement effective knowledge management strategy and establish a knowledge team through such interdisciplinary and cross-level team so as to make the team utilize resources, knowledge and complement their abilities, thus benefiting all the team members. Such team helps organizations to learn from each other's knowledge and ability as well as knowledge integration between organizations so as to create new interdisciplinary knowledge.

Establish Teachers' Knowledge Base. Information technology can increase the creation, storage and sharing within an organization as well as the width, depth, quality and speed of application. Thus it can be seen that information is closely related to knowledge management, and information technology can be used to fully combine teachers and knowledge, gather and connect massive excellent teaching knowledge and experience in a systematic way, and with the help of the sharing platform and communication channel provided by information technology, teachers can obtain the knowledge they need. By making teachers' implicit professional knowledge and teaching experience explicit and documented, other teachers can share the knowledge and give feedback so as to increase the value and application of knowledge.

Effectively classify and collate teachers' archives, teaching notes, papers, references and other tacit knowledge to make knowledge become document, archives, electronic materials stored in the knowledge database. Through using knowledge management tools, teachers can fully use and establish knowledge database, obtain and mine knowledge to obtain their needed knowledge and promote the sharing and exchange of knowledge within schools.

Establish Incentive Mechanism of Knowledge Sharing. Most of teachers' professional knowledge is tacit knowledge and teachers' willingness and initiative to share knowledge is not strong, so schools need to establish an effective mechanism to promote knowledge sharing, actively create space and opportunities for knowledge sharing so as to make teachers willing to communicate and exchange knowledge, share others' knowledge and enthusiastically contribute their own knowledge.

Finally, teachers' knowledge management can be really achieved so as to fundamentally promote the rapid growth of young teachers. 


\section{Conclusion}

Starting from the theory of knowledge management and according to characteristics of college teachers, this paper analyzes the contents and process of teachers' knowledge management, and establishes a knowledge management based young teacher cultivation mechanism according to such contents and process. Through means like tutorial system and cooperative teaching, young teachers can directly obtain tacit knowledge from senior teachers and improve their teaching ability. Knowledge base is established throughout the campus so that teachers can share knowledge, promote the application and innovation of knowledge through information technology so as to promote the growth of teachers in professional knowledge, improve their scientific research ability and finally, young teachers can rapidly grow into the main force of the development of colleges and universities.

\section{Acknowledgements}

Project: Periodic result of Xi' an Social Science Planning Fund Project 15Y49 'Research into Demand for Compound Foreign Language Talents in Xi' an against the Background of International Metropolis and Cultivation Model"

\section{References}

[1] Zhang Lin, Developmental Evaluation- the Ladder of College Young Teachers' Growth [J]. Journal of Inner Mongolia Normal University: Education Science Edition, 2005, 11.

[2] Liu Ruixian. Growth Path and Characteristics of Young College Teachers [J].China's Higher Education, 2008, 2.

[3] Li Cuiling. Research and Design o Knowledge Management System for College Teachers [D].Beijing: Beijing Jiaotong University, 2006.

[4] Yu Haitang. Deconstruction of Knowledge Management at Colleges and Universities [J]. Modern Education Science, 2003, 4. 